\title{
Attempt of basin-scale sediment quality standard establishment for heavy metals in coastal rivers
}

\author{
Qunqun Liu ${ }^{\text {a, b }}$, Yanqing Sheng ${ }^{\text {a, }{ }^{*} \text {, Ming Jiang }}{ }^{\text {a, b }}$, Guoqiang Zhao a, b, Changyu Li ${ }^{\text {a, b }}$ \\ ${ }^{a}$ Research Center for Coastal Environment Engineering Technology of Shandong Province, Yantai Institute of Coastal Zone Research, Chinese Academy of \\ Sciences, Yantai, China \\ ${ }^{\mathrm{b}}$ University of Chinese Academy of Sciences, Beijing, China
}

\section{H I G H L I G H T S}

- Standards of marine sediment and soil quality were inapplicable to river sediments.

- Basin-scale heavy metal SQSs could be used in river sediment management.

- Metal partition between sediment and porewater was affected by outer input.

- Evaluated results confirmed basinscale heavy metal SQSs were feasible.

\section{A R T I C L E I N F O}

\section{Article history:}

Received 20 September 2019

Received in revised form

1 December 2019

Accepted 8 December 2019

Available online 11 December 2019

Handling Editor: Martine Leermakers

\section{Keywords:}

Heavy metal

Basin-scale sediment

Sediment quality standards

Sediment quality guidelines

Coastal rivers

\section{G R A P H I C A L A B S T R A C T}

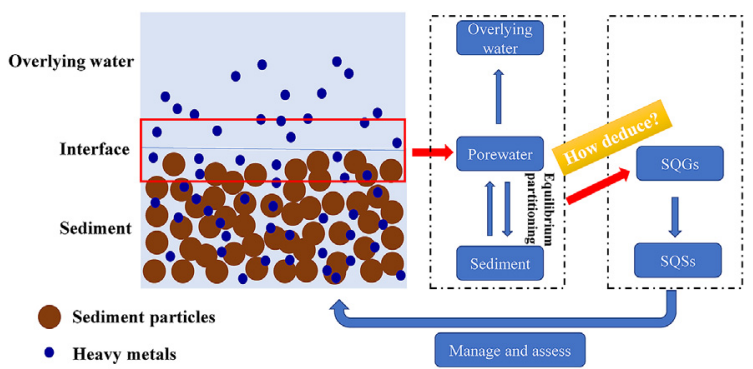

\begin{abstract}
A B S T R A C T
Heavy metal sediment quality standards (SQSs) derived from sediment quality guidelines (SQGs) are crucial in risk evaluation and environmental management. However, the establishment of SQSs is quite complex, especially for heavy metals. This study attempted to establish basin-scale SQSs for $\mathrm{Cd}, \mathrm{Cu}, \mathrm{Pb}$ and $\mathrm{Zn}$ based on SQGs combined with water quality standards in two coastal rivers in North China, named Jiaolai River (JL) and Jiahe River (JR), respectively. The spatial distribution, fraction, partition coefficients and environmental risk of heavy metals in sediments-porewater were investigated. The results showed that most heavy metals in sediments in JH were higher than those in JL, however, in the porewater, it exhibited an opposite trend. The geochemical fraction showed that most heavy metals in sediments were dominated by residual fraction. The partition of heavy metals between sediment and porewater were mainly affected by both sediment and porewater properties, and exogenous input of heavy metals. Contamination factors showed that $\mathrm{Cd}$ in sediment posed high pollution degree; the interstitial water criteria toxicity units and Nemerow Indexes suggested that heavy metal toxicities in porewater were low. The basin-scale heavy metal SQGs were calculated based on porewater quality derived from surface water quality standards using the modified equilibrium partitioning approach. The basin-scale heavy metal SQGs was classified with different grades to deduce the SQSs. Evaluated results of heavy metals in sediments based on SQSs showed lower potential bio-toxic effects in two rivers. In total, basin-scale SQGs for heavy metals were feasible for basin-scale SQSs establishment in coastal rivers.
\end{abstract}

(c) 2019 Elsevier Ltd. All rights reserved.

\footnotetext{
* Corresponding author.

E-mail address: yqsheng@yic.ac.cn (Y. Sheng).
} 


\section{Introduction}

Heavy metal pollution in aquatic systems has been a global environmental problem due to heavy metal biotoxicity, nonbiodegradability, persistence, and bio-enrichment in food webs (Liu et al., 2018a). When entering the water column, heavy metals are prone to scavenging by suspended particulate matter and are subsequently absorbed and deposited into the sediments (Zhang et al., 2017). However, sediment-associated heavy metals can be released again due to depositional environment changes (Zhang et al., 2018; Liu et al., 2019). Therefore, the actual contamination assessment of heavy metals in sediments is crucial for the environment, aquatic organisms, and human safety.

Sediment quality standards (SQSs) are criteria for sediment quality assessment and in response to regulatory programs in the legal system. Presently, there are no national SQSs for heavy metal presence in rivers for numerous countries. Accordingly, some practical problems fail to be solved, such as quantification of dredging, evaluation of treatment and remediation, and definition of sediment function. In China, although the Marine Sediment Quality (GB18668-2002) divides sediments into three levels based on environmental quality, this standard is not applicable for terrestrial sediments due to the differences of sediment properties and specific protection objectives. Similarly, the Environmental Quality Standard for Soils (GB15618-1995) still is not applicable for sediments due to different conditions; nevertheless, this standard is chronically referenced for sediment management (Chen et al., 2016; Zang et al., 2017).

Generally, SQSs can be induced by corresponding sediment quality guidelines (SQGs), which are widely applied in pollutant control. Heavy metal SQGs are related to properties, bioavailable fractions in sediments, and protection objectives (Chen et al., 2007). Thus, variable sediment properties and different protection objectives result in great difficulties to establish SQGs based on waters on a large regional scale (Gao et al., 2015). Therefore, basin-scale SQGs would be more promising and reasonable. Moreover, a watershed always includes different water function zones based on different protection objectives. Accordingly, the thresholds of heavy metal SQGs in different water function zones are different. Therefore, it is crucial to establish heavy metal SQGs for the establishment of SQSs based on different water function zones. The equilibrium partitioning approach (EqPA) is a preferred method for establishing heavy metal SQGs based on the thermodynamic equilibrium between sediments and porewater (US EPA, 1989; Liu et al., 2017). This method makes full use of the water quality standards and directly introduces the bioavailability of heavy metals in overlying water into the SQGs (Burton, 2002). Meanwhile, the application of water quality standards in porewater could provide scientific information for water environment management (Huo et al., 2013).

Coastal rivers generally have special geomorphological characteristics resulting from the effects of land-sea interaction. Moreover, coastal rivers always have been taken responsibilities of landbased pollutant discharge, especially for heavy metals (Islam et al., 2018). Therefore, establishing heavy metal SQGs and SQSs of coastal rivers is of great significance to the marine environmental protection. The aims of this study are to (i) investigate the spatial and fraction distribution of $\mathrm{Cd}, \mathrm{Cu}, \mathrm{Pb}$, and $\mathrm{Zn}$ in coastal river sediments; (ii) identify the partition behavior of heavy metals between sediments and porewater; (iii) assess heavy metal contamination in sediments through porewater; (iv) attempt to establish heavy metal SQSs for coastal rivers based on SQGs combined with water quality standards.

\section{Materials and methods}

\subsection{Study area}

Both Jiaolai River (JL) and Jiahe River (JH) are typical coastal rivers located in the Shandong Peninsula (China) (Fig. 1), an area dominated by foothills. The length of the $\mathrm{JH}$ is $\sim 140 \mathrm{~km}$, and the total watershed area spans $2296 \mathrm{~km}^{2}$. The JL stretches for $\sim 130 \mathrm{~km}$, and covers an area of $5478.6 \mathrm{~km}^{2}$. Taking Yaojia Village, Pingdu City as a watershed, the JL flows southward into the Jiaozhou Bay and northward into the Laizhou Bay. The average annual runoffs of JL and $\mathrm{JH}$ are $2.53 \times 10^{9}$ and $2.81 \times 10^{9} \mathrm{~m}^{3}$, respectively. There are several industrial zones (chemical engineering, electronics, and mechanical manufacturing) located on both sides of JL, causing industrial waste discharge along the river. As irrigated agriculture is along the JL, the no-point source pollution (chemical fertilizers and pesticides) also threatens the river environment. The $\mathrm{JH}$ is also mainly used for agricultural irrigation, while it has a lower number of industries along both banks of the river compared to JL. However, with the development of industries and agriculture, the two rivers have been partially polluted by industry-agriculture wastes.

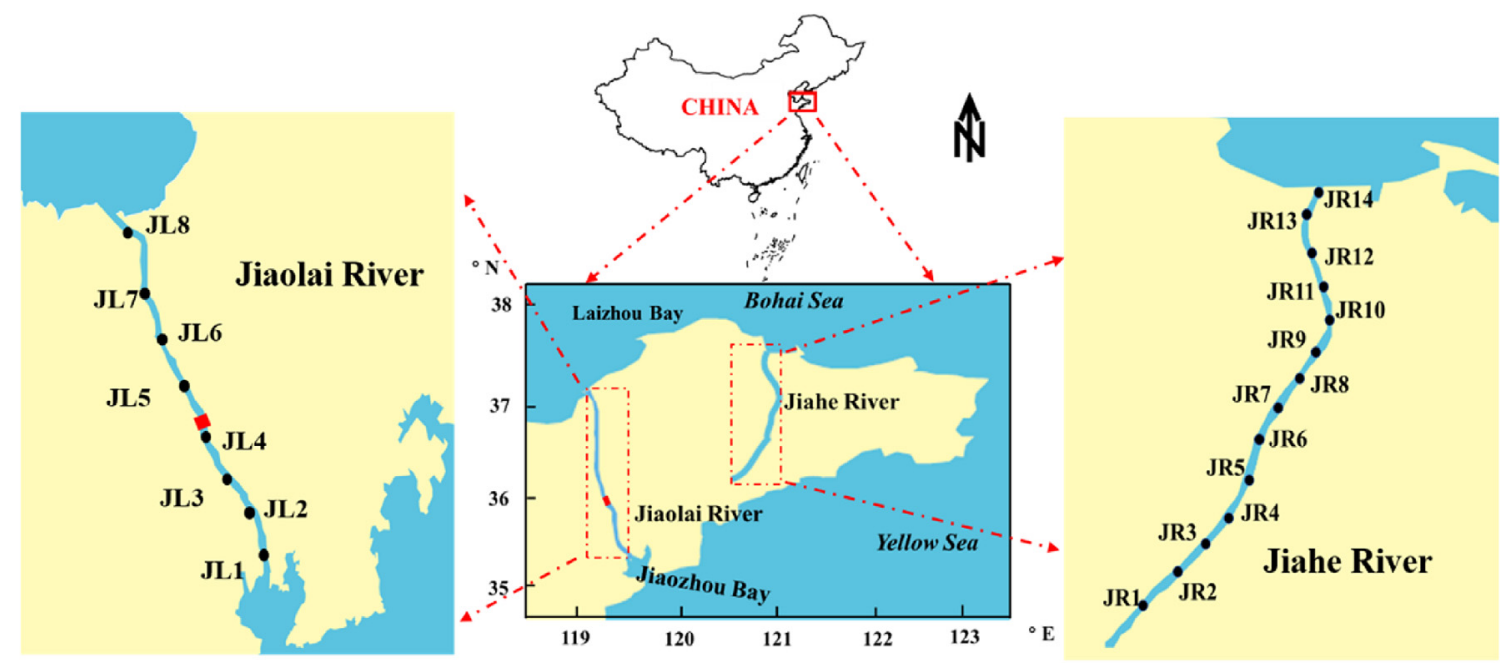

Fig. 1. Location of sampling sites. 


\subsection{Sampling and pretreatment}

Eight (JL1-JL8) and fourteen (JH1-JH14) sediment samples were collected from the two rivers in October 2018 (Fig. 1). Transportation, pretreatment, and preservation of samples were strictly conducted according to standard methods (CENPA, 2002). Sampling sites were recognized by a GPS. Surface sediments $(0-10 \mathrm{~cm})$ were collected by a Peterson grab sampler and stored at $4{ }^{\circ} \mathrm{C}$. For the pretreatment, a portion of each sediment was freeze-dried, ground, and passed through a $100 \mu \mathrm{m}$ nylon mesh to obtain consistent physical properties for heavy metals and total organic carbon (TOC). A portion of no-ground sediment was destined for particle size detection. The porewater was obtained by centrifuging (6000 rpm, $30 \mathrm{~min}$ ), and then filtered with a $0.45 \mu \mathrm{m}$ cellulose acetate membrane (Han et al., 2014). Every $5 \mathrm{~mL}$ volume of filtered porewater was acidified with $0.2 \mathrm{~mL} 1 \mathrm{M}$ nitric acid to ensure $\mathrm{pH}<2$, and stored at $4{ }^{\circ} \mathrm{C}$ until index determination.

\subsection{Analytical produce}

Dissolved $\mathrm{Cd}, \mathrm{Cu}, \mathrm{Pb}$, and $\mathrm{Zn}$ in porewater were analyzed using inductively coupled plasma-mass spectrometry (ICP-MS, PerkinElmer NexlON 300Q, USA). For total heavy metal concentration analysis, the pretreated sediments $(0.2500 \mathrm{~g} \pm 0.0001)$ were transferred into Teflon tubes and digested with a mixed solution of $\mathrm{HNO}_{3}+\mathrm{HF}+\mathrm{HClO}_{4}(8: 5: 2, \mathrm{v} / \mathrm{v})$ in a microwave digestion instrument (Tank Basic, Sineo Microwave Chemistry Technology Co., LTD, China) and then analyzed by ICP-MS. The particle sizes were tested by a laser particle size analyzer (Malvern Mastersizer, 2000F, UK). The TOC was measured using a TOC analyzer (Vario Micro cube, German). Acid volatile sulfides (AVS) were analyzed following a modified cold diffusion procedure (Sheng et al., 2015), where an aliquot of sediment ( $10 \mathrm{~g}$ wet weight) was purged for $1 \mathrm{~h}$ with $15 \mathrm{~mL}$ of $9 \mathrm{M} \mathrm{HCl}$ under $\mathrm{N}_{2}$ flux. The $S$ concentrations for AVS trapped in $\mathrm{ZnS}$ were measured using iodometric titration. The supernatant of a 1: $5(\mathrm{w} / \mathrm{v})$ suspension extracted with ultra-pure water was employed for the determination of electric conductance (EC), pH, and salinity of sediments.

The heavy metal fraction analysis was conducted using modified Bureau Communautaire de Référence (BCR) sequential extraction procedure (Rauret et al., 1999). The metal fraction was divided into the acid-soluble fraction (F1), reducible fraction (F2), oxidizable fraction (F3), and residual fraction (F4); determination details are listed in Table S1.

\subsection{Quality assurance and quality control}

All determinations were conducted in accordance with strict quality control. Procedure blank samples and reagent blanks were applied across the entire process. The precision of analysis for dissolved heavy metals in porewater was validated through heavy metal solution standards with control, and recoveries were within $92 \%-107 \%$. For total and fractionation analysis, sediment standard reference materials GBW 40376 and GBW 07311 (GSD-11) were used for quality assurance. The recoveries and relative deviations were $90 \%-108 \%$ and $<8 \%$, respectively.

\subsection{Heavy metal SQGs calculation}

The EqPA is a popular method for establishing SQGs of heavy metals based on the thermodynamic equilibrium between sediment and porewater (US EPA, 1989; Liu et al., 2017). According to the theory of EqPA, water quality standards can be applied to porewater contaminants; the SQG values can be defined by the concentration of contaminants in the sediment that was in equilibrium with the concentrations of porewater quality standards derived from surface water standards (Chen et al., 2007). Considering the bioavailability and mobility of heavy metals, the SQGs were calculated with normalized EqPA as follows (Gao et al., 2015):

$$
\begin{aligned}
& \mathrm{SQG}=K_{p} \times W Q C_{i}+M_{R, i}+M_{A V S, i} \\
& \mathrm{SQG}=K_{p} \times W Q C_{i}+M_{R, i} \\
& K_{p}=C_{T} \times(1-A \%) / C_{i, w} \\
& M_{A V S, i}=A V S \times M_{i} \times C_{T, i} / \sum_{i}^{n=5} C_{T, i}
\end{aligned}
$$

where $K_{p}$ is the partitioning coefficient between sediments and porewater; $W Q C_{i}$ are the corresponding water quality standards from the optimized environmental quality standards for surface water of China (EQSSW) (CSEPA, 2002), which match the classification of water quality standards of porewater based on different water function zones (Table 1 ); $M_{R, i}$ is the residual fraction concentration of heavy metal in sediments $\left(\mathrm{mg} \mathrm{kg}^{-1}\right) ; M_{A V S, i}$ is the concentration of heavy metals $(\mathrm{Cu}, \mathrm{Cd}, \mathrm{Zn}$, and $\mathrm{Pb})$ associated with AVS in sediments $\left(\mu \mathrm{mol} \mathrm{g}^{-1}\right) ; C_{T}$ is the total concentration of heavy metals in sediments $\left(\mathrm{mg} \mathrm{kg}^{-1}\right) ; A$ is the percentage of residual heavy metals in the sediments (\%); and $C_{i, w}$ is the concentration of heavy metals in porewater $\left(\mu \mathrm{g} \mathrm{L}^{-1}\right)$.

\subsection{Assessment of heavy metal contamination}

\subsubsection{Interstitial water criteria toxicity units}

The toxicity level of porewater was assessed using the method of interstitial water criteria toxicity units (IWCTU) and Nemerow indexes (NI) (Tang et al., 2016), which were calculated as follows:

$$
\operatorname{IWCTU}_{M_{e}}=\left[M_{e}\right]_{i, w} / F C V_{M_{e}}
$$

Table 1

The classification of original and optimized quality standards for sediment porewater $\left(\mathrm{mg} \mathrm{L}^{-1}\right)$.

\begin{tabular}{lllll}
\hline Threshold & $\mathrm{Cd}$ & $\mathrm{Cu}$ & $\mathrm{Pb}$ & $\mathrm{Zn}$ \\
\hline \multicolumn{2}{l}{ Original standards for surface water } & & & \\
I & 0.001 & 0.01 & 0.01 & 0.05 \\
II & 0.005 & 1.0 & 0.01 & 1.0 \\
III & 0.005 & 1.0 & 0.05 & 1.0 \\
IV & 0.005 & 1.0 & 0.05 & 2.0 \\
V & 0.01 & 1.0 & 0.10 & 2.0 \\
\hline \multicolumn{2}{l}{ Optimized standards for sediment porewater } & & \\
I & 0.001 & 0.01 & 0.01 & 0.05 \\
II & 0.005 & 0.5 & 0.05 & 1.0 \\
III & 0.01 & 1.0 & 0.10 & 2.0 \\
\hline
\end{tabular}

For surface water: Grade I: it is applicable to drinking source water and national nature reserves; II: the first-class protection area of surface water source area of centralized drinking water, habitat of rare aquatic organisms, fishery and shrimp production field, rope bait field of larvae and juveniles; III: secondary protection areas of surface water sources, wintering grounds of fish and shrimp, migration passages, aquaculture areas and other fishery waters and swimming areas of centralized drinking water; IV: general industrial water use areas and recreational water areas where human body is not in direct contact; V: agricultural water use areas and waters with general landscape requirements.

For sediment porewater: I: the applicable area is same as Grade I of surface water; II: the applicable area is same as Grade II and III of surface water; III: the area is same as above Grade IV and V. 
$N I=\left\{\left[(I W C T U)_{\text {max }}^{2}+(I W C T U)_{\text {mean }}^{2}\right] / 2\right\}^{1 / 2}$

where $\left[M_{e}\right]_{i, w}$ is the concentration of dissolved heavy metal $i$ in porewater $\left(\mu \mathrm{g} \mathrm{L}^{-1}\right)$, and $F C V_{M_{e}}$ represents the final chronic value of heavy metals ( $\mu \mathrm{g} \mathrm{L}^{-1}$ ) (US EPA, 2002, 2005). If IWCTU >1, biota may suffer from potential toxicity. According to the NI values, the porewater quality can be classified into five classes, as shown in Table S2.

\subsubsection{Pollution load index and contamination factor}

The pollution load index (PLI) and contamination factor (CF) were obtained using the following formulas:

$C F=C_{M_{e}} / C_{B}$

$P L I=\sqrt[n]{\left(C F_{1} \times C F_{2} \times \ldots \times C F_{n}\right)}$

where $\mathrm{CF}$ is the contamination factor based on the proportion of heavy metal concentration $\left(C_{M_{e}}\right)$ to its corresponding background value $\left(C_{B}\right)\left(\mathrm{mg} \mathrm{kg}^{-1}\right)$ (Shi et al., 2016), and it is interpreted according to four degrees of contamination, as presented in Table S2; PLI indicates the comprehensive contamination of measured heavy metals in sediments; $n$ represents the number of selected heavy metals.

\subsubsection{Mean sediment quality guideline quotient ( $m S Q G-Q$ )}

The $\mathrm{mSQG}-\mathrm{Q}$ proposed by Long and MacDonald (1998) has been a widely applied method (Cheng and Yap, 2015; Liu et al., 2017). It considers the bioavailability and bio-toxic effects of heavy metals, and its credibility, sensitivity, and robustness are higher than those of other methods (Caeiro et al., 2015). The mSQG-Q was obtained through computing mean quotients for multiple heavy metals by following formula:

$\mathrm{mSQG}-\mathrm{Q}=\sum_{i=1}^{n}\left(C_{i} / S Q G_{i}\right) / n$

where $C_{i}$ represents the concentration of heavy metal $i$ in sediments $\left(\mathrm{mg} \mathrm{kg}^{-1}\right) ; n$ is the number of heavy metals; $S Q G_{i}$ is the SQG of heavy metal $i\left(\mathrm{mg} \mathrm{kg}^{-1}\right)$. Based on $\mathrm{mSQG}-\mathrm{Q}$ values, the sediments' quality is defined as: $\mathrm{mSQG}-\mathrm{Q} \leq 0.1$, unimpacted or lowest potential bio-toxic effects; $0.1<\mathrm{mSQG}-\mathrm{Q}<1$, moderate impact potential bio-toxic effects; $\mathrm{mSQG}-\mathrm{Q} \geq 1$, high impact potential biotoxic effects.

\subsection{Statistical analysis}

The data was statistically analyzed using SPSS software. Data normality was detected by the Kolmogorov-Smirnov $(\mathrm{K}-\mathrm{S})$ test. Correlations were calculated with Pearson correlation analysis, and a $P<0.05$ was regarded as a significant correlation level.

\section{Results and discussion}

\subsection{The physicochemical properties and heavy metal distribution of sediments}

The sediments' properties are shown in Table S3. The pH of sediments in JL and JH ranged from 4.78 to 7.90 and 7.73 to 8.20 , respectively. The low $\mathrm{pH}$ in $\mathrm{JL}$ was related to industrial acid wastewater discharge along river. The mean values of salinity and EC in sediments were $1.0 \%$ and $1.8 \mathrm{mS} \mathrm{cm}^{-1}$ in JL, $1.3 \%$ and
$2.3 \mathrm{mS} \mathrm{cm}^{-1}$ in $\mathrm{JH}$, respectively. The coefficient of variation (CV) of EC and salinity in JH was higher than those in JL, indicating a greater variation of these parameters along $\mathrm{JH}$. With regard to particle size, sediments were all dominated by sand, followed by silt and clay, which was primarily due to rainwater erosion and transport effects. The average TOC concentration in JH was $0.94 \%(0.65 \%-1.97 \%)$, and high values were primarily observed in the middle reach, where the slow water current contributed to organic matter deposition. Compared to JH, TOC in JL was low (0.25\%), which was attributed to frequent artificial disturbance of sediments, such as dredging and sand excavation. Furthermore, the AVS in two rivers was uneven based on CV analysis, because it was greatly affected by TOC, redox condition, and sulfate reducing bacteria (Allen et al., 1993). As shown in Table S3, the inhomogeneity of TOC in JH and JL was partially responsible for this phenomenon. Moreover, the heavy metal SQGs was closely related to the AVS in sediments, because AVS could combine with sulfophilic metals ( $\mathrm{Cd}, \mathrm{Cu}, \mathrm{Ni}, \mathrm{Pb}$, and $\mathrm{Zn}$ ) to form insoluble metal sulfides, significantly reducing their bioavailability (Toro et al., 1991).

As shown in Table S4, the average total heavy metal concentrations $\left(\mathrm{mg} \mathrm{kg}^{-1}\right)$ in sediments in JL decreased according the following sequence: $\mathrm{Zn}(62.59 \pm 49.56)>\mathrm{Pb}(14.05 \pm 3.62)>\mathrm{Cu}$ $(10.57 \pm 2.66)>\mathrm{Cd}(0.33 \pm 0.08)$. The $\mathrm{CV}$ values of $\mathrm{Cd}, \mathrm{Cu}$, and $\mathrm{Pb}$ were low ( $<25 \%$, Table S4), exhibiting a homogeneous distribution in JL. A different spatial distribution was observed for Zn (CV 79.18\%), indicating that $\mathrm{Zn}$ was variable at different sites. The mean total heavy metal concentrations $\left(\mathrm{mg} \mathrm{kg}^{-1}\right)$ in JH followed the order: $\mathrm{Zn}(98.96 \pm 45.61)>\mathrm{Cu}(34.08 \pm 10.81)>\mathrm{Pb}$ $(30.90 \pm 6.75)>\mathrm{Cd}(0.61 \pm 0.67)$ (Table S4), which indicated a great difference compared to JL. In particular, the $\mathrm{Cd}$ and $\mathrm{Zn}$ in JH 13 and JH14 were approximately three times higher than at other sites (Fig. 2(a)), which was probably due to their location at the estuary, where heavy metals were more easily scavenged (Pan and Wang, 2012). Moreover, regarding CV values, the highest variation was found in $\mathrm{Cd}$ (109.80\%), whereas $\mathrm{Pb}$ exhibited relatively a homogeneous distribution (21.83\%).

Usually, grain size and TOC are major factors for the regulation of heavy metal spatial distribution in sediments (Ma et al., 2019). According to Pearson's correlation analysis (Table S5), the TOC exhibited a significant positive correlation with $\mathrm{Zn}(P<0.05)$ in JL, suggesting the distribution of $\mathrm{Zn}$ was controlled by TOC in this area. The fine grain size (silt + clay) of sediments in JH was only significantly correlated with $\mathrm{Pb}(P<0.05)$, indicating that the distribution of $\mathrm{Pb}$ in sediments in $\mathrm{JH}$ was controlled by grain size (Soliman et al., 2019). Furthermore, the grain size and TOC showed a weak correlation with most heavy metals in this study. This phenomenon suggested that heavy metals in the sediment were mainly contaminated by point sources (such as industrial and municipal wastewater) (Neyestani et al., 2016).

Geochemical fractions of heavy metals in JL are portrayed in Fig. 2(a). Among the four fractions, the F1 represents the bioavailable fraction, and a sum of F1, F2, and F3 is considered as the mobile fraction (Rauret et al., 1999). All heavy metals were dominated by the $\mathrm{F} 4$, on average, and approximately $48 \%$ of $\mathrm{Zn}, 72 \%$ of $\mathrm{Cu}, 79 \%$ of $\mathrm{Cd}$, and $65 \%$ of $\mathrm{Pb}$ fall into this fraction. The high percentage of $\mathrm{F} 4$ showed a minor ecological risk posed to biota. Only $\mathrm{Zn}$ was presented at a high proportion at F1 (23\%), which indicated high potential ecological risk, while the remaining heavy metals occupied minor proportions ( $<7 \%$ ). Higher percentages of $\mathrm{Pb}(28 \%)$ and $\mathrm{Zn}$ (21\%) were found in F2. Generally, all heavy metals accounted for the lower proportions $(<10 \%)$ in F3 at all sites. Overall, average proportions of mobile fractions of heavy metals in sediments in JL occurred in the descending order: $\mathrm{Zn}(52 \%)>\mathrm{Pb}(35 \%)>\mathrm{Cu}$ (28\%) > Cd (20\%).

The fraction partitions in $\mathrm{JH}$ were less uniform than those in JL. 

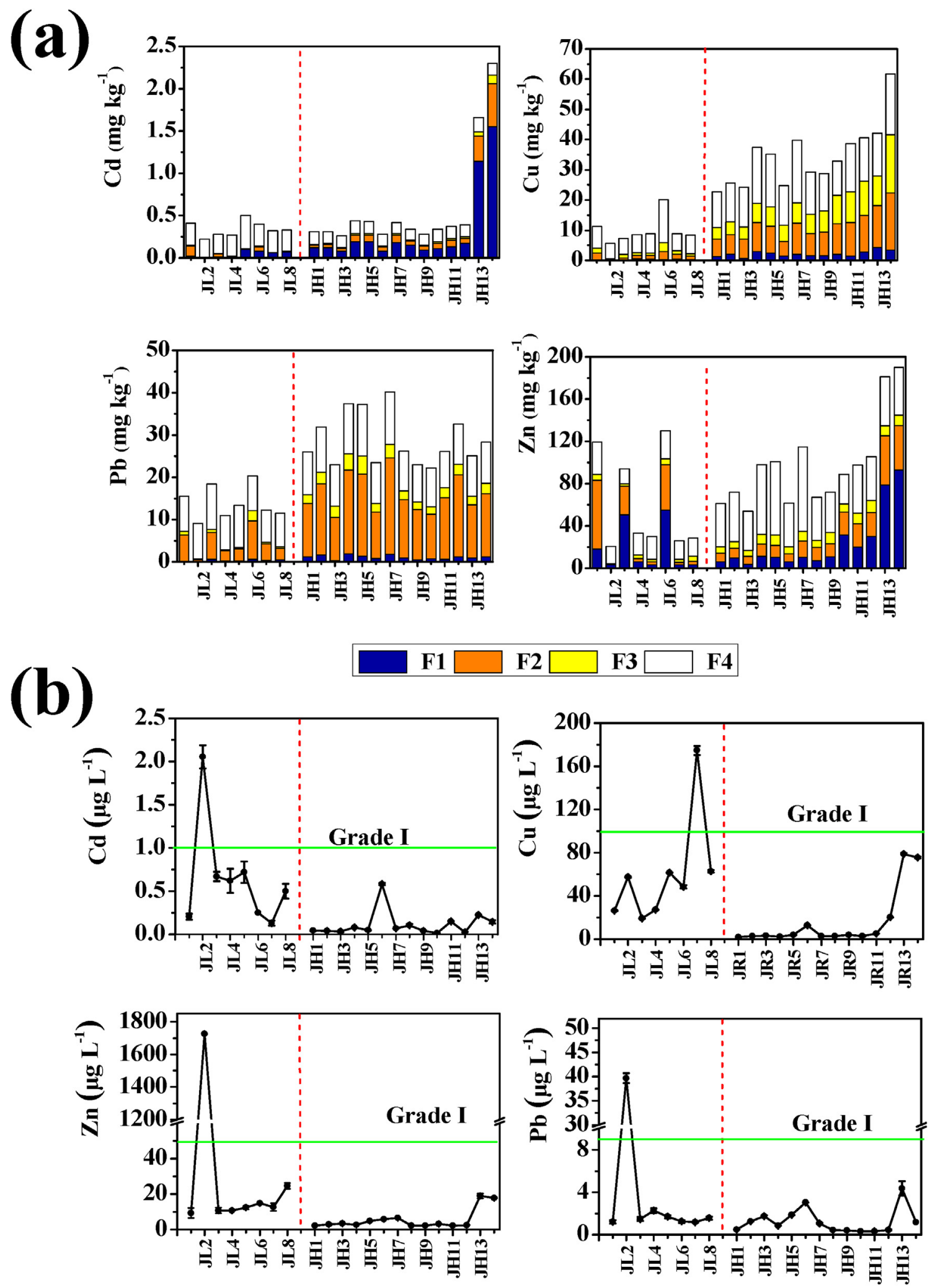

Fig. 2. Total and different chemical fraction concentrations of heavy metals in sediments (a); heavy metal concentrations in porewater in JL and JH (b).

The $\mathrm{Cu}$ showed the highest percentages of F4 (45\%), while F2 and F3 also accounted for higher proportions (>20\%). For Pb, F2 was the dominated fraction (52\%), followed by F4 (36\%), F3 (9\%), and F1 (4\%). This result was consistent with previous reports (Morillo et al.,
2004; Gu and Lin, 2016), suggesting that Pb was mainly associated with F2. Notably, both $\mathrm{Pb}(<4 \%)$ and $\mathrm{Cu}(<6 \%)$ had low percentages in $\mathrm{F} 1$ at all sites. Furthermore, the dominant fraction of Cd was F1 (43\%), and a similar result was found in the surface sediments from 
the Jinjiang River (Liu et al., 2018b) and Jiaozhou Bay, China (Lin et al., 2016), indicating that Cd was primarily associated with anthropogenic sources (Alves et al., 2018). Similar to $\mathrm{Cu}$, the dominated fraction of $\mathrm{Zn}$ was also F4 (54\%), meanwhile, F2 accounted for a high proportion (19\%). For the mobility sequence in sediments in $\mathrm{JH}, \mathrm{Pb}$ showed the highest proportion (64\%), followed by Cd (63\%), Cu (55\%), and $\mathrm{Zn} \mathrm{(46 \% ).}$

\subsection{Heavy metal concentrations and contamination in porewater}

The heavy metal concentrations in porewater are presented in Fig. 2(b). Mean concentrations ( $\left.\mu \mathrm{g} \mathrm{L}^{-1}\right)$ in JL were in the following descending order: $\mathrm{Zn}(227.72 \pm 605.55)>\mathrm{Cu}(59.74 \pm 49.51)>\mathrm{Pb}$ $(6.30 \pm 13.49)>\mathrm{Cd}(0.64 \pm 0.61) . \mathrm{Cd}, \mathrm{Pb}$, and $\mathrm{Zn}$ concentrations in JL were higher than Grade I of the EQSSW (CSEPA, 2002) at site JL2, including $\mathrm{Cu}$ at site JL7. The average values $\left(\mu \mathrm{g} \mathrm{L}^{-1}\right)$ in JH were in the descending order of: $\mathrm{Cu}(15.68 \pm 26.58)>\mathrm{Zn}(5.53 \pm 5.65)>\mathrm{Pb}$ $(1.27 \pm 1.18)>\mathrm{Cd}(0.11 \pm 0.15)$. Compared to JL, ranges and average values in JH were low, and all metals at all sites satisfied Grade I.

Generally, heavy metals weakly associated (mobile fractions) with sediments are prone to their re-release into porewater (Ji et al., 2018). In this study, although heavy metals in porewater in JL were higher than those in $\mathrm{JH}$, the total content of heavy metals and their mobile fractions in sediments of JL was lower than that in $\mathrm{JH}$ (Fig. 2(a)). This phenomenon was probably related to the external input of heavy metals with industrial wastewater discharge along the river, resulting in high concentrations in porewater. Furthermore, lower TOC and coarse sediments (grain size) in JL (Table S3) were also not favorable to trap heavy metals from porewater (Ma et al., 2019). Additionally, the lower pH in JL could also promote the release of heavy metals due to cation exchange and competitive adsorption increase (Yao et al., 2016; Wang et al., 2018).

Heavy metals in porewater represent the bioavailable part in sediments, which can be considered as essential indicators of toxic effects (Tang et al., 2016). The IWCTU can reflect the degree of heavy metal contamination in the porewater. In Table S6, the heavy metals in porewater in JL exhibited a low contamination degree on the whole. IWCTU values $>1$ were only found at $\mathrm{Zn}$ (JL2) and $\mathrm{Cu}$ (JL7), posing long-term toxicity effects to aquatic organisms. For the $\mathrm{NI}$, high values were observed at JL2 (1.25) and JL7 (1.70), suggesting suffering from a slight contamination degree. The NI values at other sites were below 1, implying no impact at these sites. In JH, the IWCTU values were $<1$ except for $\mathrm{Cu}$ at JH12-JH14. The NI $<1$ was observed at $\mathrm{JH} 1-\mathrm{JH} 11$, indicating no adverse impacts at these sites. However, the NI values in JH13 and JH14 were 3.89 and 3.69, respectively, indicating strong contamination levels. The values of the IWCTU and NI indicated that although several heavy metals posed some adverse effects to biota, the pollution and toxicity of heavy metals in porewater was low at most sites.

\subsection{Distribution relationships of heavy metals in porewater and sediments}

Heavy metals consistently exhibit a migration trend from sediments to porewater, affected by their physicochemical properties and environmental factors (Ji et al., 2018). In this study, the ratio of total concentrations of heavy metals in sediments and porewater, as the partition coefficient $\left(K_{d}\right)$, was used to determine the heavy metal migration ability. The calculation was expressed as:

$K_{d}=C_{s} / C_{w}$

where $C_{s}\left(\mu \mathrm{g} \mathrm{g}^{-1}\right)$ and $C_{w}\left(\mu \mathrm{g} \mathrm{L}^{-1}\right)$ are heavy metal contents in sediments and porewater at equilibrium (Hierro et al., 2014). The lower $K_{d}$ values indicate that heavy metals in sediments easily
Table 2

The partition coefficients of heavy metals between sediments and porewater.

\begin{tabular}{lllll}
\hline & $\mathrm{Cd}$ & $\mathrm{Cu}$ & $\mathrm{Pb}$ & $\mathrm{Zn}$ \\
\hline $\mathrm{JL}$ & & & & \\
Min & 0.11 & 0.05 & 0.23 & 0.01 \\
Max & 2.46 & 0.42 & 16.13 & 4.11 \\
Mean & 1.05 & 0.24 & 8.97 & 3.30 \\
\hline JH & & & & \\
Min & 0.43 & 0.56 & 6.18 & 10.10 \\
Max & 21.25 & 15.31 & 83.80 & 48.73 \\
Mean & 8.52 & 7.60 & 43.34 & 25.51 \\
\hline
\end{tabular}

migrate to porewater (Ji et al., 2018).

The $K_{d}$ values in JL and JH are summarized in Table 2. Generally, the heavy metals occupied by higher mobile fraction in sediments would exhibit lower $K_{d}$ values, as they are easily released into porewater (Ji et al., 2018). However, an unusual phenomenon was observed for $\mathrm{Zn}$ and $\mathrm{Pb}$ in JL. The mobile fraction concentrations of $\mathrm{Zn}$ and $\mathrm{Pb}$ were higher in $\mathrm{JH}$, however, their $K_{d}$ values were also higher. The partition equilibrium of heavy metals between sediments and porewater usually depends on complexant properties in porewater, external heavy metals import, and sediment composition, except for mobile fractions (Wang et al., 2018). The reason of this phenomenon in this study was due to external $\mathrm{Pb}$ and $\mathrm{Zn}$ discharge into porewater (as discussed in Section 3.2), which altered the original partition equilibrium between sediments and porewater. Similar results were also observed for $\mathrm{Pb}$ and $\mathrm{Zn}$ in $\mathrm{JH}$. Generally, the partition coefficients $\left(K_{d}\right)$ of heavy metals in JH were higher than those in JL. This was because heavy metals in porewater in $\mathrm{JL}$ were higher than those in $\mathrm{JH}$, while in sediments they were lower than $\mathrm{JH}$.

\subsection{Heavy metal SQGs}

Generally, there are many water functional zones in a specific watershed, and to ensure this, heavy metal SQGs need to be classified into different grades to avoid the effects of heavy metal release. In this study, the grade classification of heavy metal SQGs was set based on optimized EQSSW for porewater (Table 1). The original heavy metal SQGs of the same grade varied greatly among different sites, especially for $\mathrm{Zn}$ (e.g., $68.49-1610.73 \mathrm{mg} \mathrm{kg}^{-1}$ ) in both JL and JH. Apart from differences in the chemical fractionation and concentration of heavy metals, variations of AVS, pH, and TOC of sediments were also responsible for the large differences in heavy metal SQGs of the same grade. For example, heavy metal SQGs can be greatly affected by AVS normalization, and AVS concentrations were variable at different sites (Table S3), resulting in differences between sites. Therefore, to ensure the accuracy of heavy metal SQGs establishment, some outliers of SQGs were eliminated at several sites, and subsequently the geometric average value of heavy metal SQGs at rest sites was calculated to obtain basin-scale SQGs (Table 3). Some great variations of SQGs between different metals were also observed. This was due to different water quality standards and partitioning coefficients (Chen et al., 2007). Similarly, all heavy metal SQGs exhibited large differences between $\mathrm{JL}$ and $\mathrm{JH}$ (Table 3). Moreover, the same heavy metal SQGs between different grades also exhibited large differences. Hence, it was not feasible to establish SQGs for rivers on a large scale, and establishment for basin-scale heavy metal SQGs is deemed more realistic and reasonable.

The large variations of heavy metal SQGs values compared to other studies (Table 3) were mainly ascribed to the different SQG derivation methods and water quality guidelines, apart from sediment properties and bioavailability of heavy metals. Moreover, 
Table 3

Comparison of basin-scale SQGs between study area and area of other studies $\left(\mathrm{mg} \mathrm{kg}^{-1}\right)$.

\begin{tabular}{|c|c|c|c|c|c|}
\hline & $\mathrm{Cd}$ & $\mathrm{Cu}$ & $\mathrm{Pb}$ & $\mathrm{Zn}$ & References \\
\hline \multicolumn{6}{|l|}{$\mathrm{JL}$} \\
\hline SQGs-I ${ }^{\text {a }}$ & 3.82 & 62.94 & 293.20 & 413.19 & This study \\
\hline SQGs-II ${ }^{b}$ & 5.16 & 67.33 & 409.70 & 1606.48 & \\
\hline SQGs-III ${ }^{c}$ & 10.65 & 136.55 & 536.70 & 2677.16 & \\
\hline \multicolumn{6}{|l|}{$\mathrm{JH}$} \\
\hline SQGs-I ${ }^{\text {a }}$ & 6.56 & 147.13 & 453.97 & 817.00 & This study \\
\hline SQGs-II ${ }^{b}$ & 22.25 & 295.55 & 1264.41 & $10,113.93$ & \\
\hline SQGs-III ${ }^{c}$ & 41.42 & 3159.97 & 2264.57 & $19,879.93$ & \\
\hline Dianchi Lake (China) & 5.56 & 53.8 & 67.8 & 106.4 & Chen et al. (2007) \\
\hline Xiangjiang River (China) & 3.56 & 92.28 & 102.79 & 1495.09 & Liu et al. (2017) \\
\hline Chaohu Lake (China) & 23.90 & 56.95 & 362.93 & 74.68 & Huo et al. (2013) \\
\hline Yangzte River (China) & 8.35 & 73.05 & 197.41 & 4120.12 & Gao et al. (2015) \\
\hline UK & 7.68 & 34 & 32.68 & 191.4 & Webster and Ridgway (1994) \\
\hline Probable effect concentration ${ }^{\mathrm{d}}$ & 4.98 & 149 & 128 & 459 & MacDonald et al. (2000) \\
\hline Risk screening value ${ }^{e}$ & 0.8 & 200 & 240 & 300 & Ministry of Ecological and Environment of China, 2018 \\
\hline CMSQS-I & 0.50 & 35.0 & 60.0 & 150.0 & CSBTS China State Bureau of Quality and Technical Supervision, 2002 \\
\hline CMSQS-II & 1.50 & 100.0 & 130.0 & 350.0 & \\
\hline CMSQS-III & 5.00 & 200.0 & 250.0 & 600.0 & \\
\hline
\end{tabular}

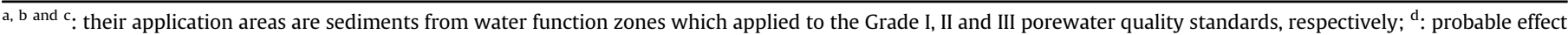

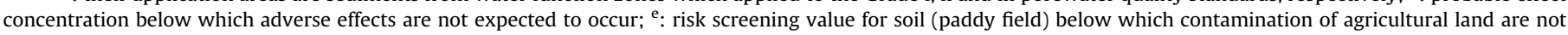
expected to occur.

different protection objectives, the non-uniformity of testing environmental factors, and acquiring biological effects also could cause different SQGs (Chen et al., 2007). In JL and JH, the heavy metal SQGs were also variable compared to CMSQS (CSBTS, 2002) and the risk screening value (Ministry of Ecological and Environment of China, 2018), which indicated that standards of marine sediment and soil quality were not suitable for river sediment management and control.

\subsection{Application and feasibility of SQSs for assessment of heavy metal contamination}

In this study, the calculated basin-scale heavy metal SQGs was tentatively considered as corresponding SQSs after normalization

Table 4

The mSQG-Q for heavy metals in sediments in JL and JH.

\begin{tabular}{|c|c|c|c|c|c|}
\hline \multirow[b]{2}{*}{ Sites } & \multicolumn{4}{|c|}{ SQG-Q } & \multirow[b]{2}{*}{ mSQG-Q } \\
\hline & Cd & $\mathrm{Cu}$ & $\mathbf{P b}$ & $\mathbf{Z n}$ & \\
\hline JL1 & 0.11 & 0.18 & 0.05 & 0.25 & 0.15 \\
\hline JL2 & 0.06 & 0.09 & 0.03 & 0.04 & 0.05 \\
\hline JL3 & 0.07 & 0.12 & 0.06 & 0.23 & 0.12 \\
\hline JL4 & 0.07 & 0.14 & 0.04 & 0.08 & 0.08 \\
\hline JL5 & 0.13 & 0.14 & 0.04 & 0.07 & 0.10 \\
\hline JL6 & 0.10 & 0.32 & 0.07 & 0.31 & 0.20 \\
\hline JL7 & 0.09 & 0.14 & 0.04 & 0.06 & 0.08 \\
\hline JL8 & 0.08 & 0.13 & 0.04 & 0.07 & 0.08 \\
\hline Mean & 0.09 & 0.16 & 0.05 & 0.14 & \\
\hline JH1 & 0.05 & 0.15 & 0.06 & 0.07 & 0.27 \\
\hline JH2 & 0.05 & 0.18 & 0.07 & 0.09 & 0.26 \\
\hline JH3 & 0.04 & 0.17 & 0.05 & 0.07 & 0.16 \\
\hline JH4 & 0.07 & 0.26 & 0.08 & 0.12 & 0.61 \\
\hline JH5 & 0.07 & 0.24 & 0.08 & 0.12 & 0.61 \\
\hline JH6 & 0.04 & 0.17 & 0.05 & 0.08 & 0.59 \\
\hline JH7 & 0.06 & 0.27 & 0.09 & 0.14 & 0.65 \\
\hline JH8 & 0.05 & 0.20 & 0.06 & 0.08 & 0.59 \\
\hline JH9 & 0.04 & 0.20 & 0.05 & 0.09 & 0.51 \\
\hline JH10 & 0.05 & 0.22 & 0.05 & 0.10 & 0.66 \\
\hline JH11 & 0.05 & 0.26 & 0.06 & 0.12 & 0.75 \\
\hline JH12 & 0.06 & 0.28 & 0.07 & 0.13 & 0.86 \\
\hline JH13 & 0.25 & 0.28 & 0.06 & 0.22 & 0.46 \\
\hline JH14 & 0.35 & 0.43 & 0.06 & 0.23 & 0.48 \\
\hline Mean & 0.09 & 0.24 & 0.06 & 0.12 & \\
\hline
\end{tabular}

The mSQG-Q: : unimpacted or lowest potential bio-toxic effects; $\square$ : moderate impact potential 
and optimization, and the corresponding SQSs were employed to assess heavy metal contamination with the method of mSQG-Q. The evaluation results of $\mathrm{MSQG}-\mathrm{Q}$ for heavy metals in sediments are shown in Table 4. In JL, all heavy metals were below their SQSs-I $(S Q G-Q<1)$ at all sites. This demonstrated that heavy metal pollution in sediments in JL was low. For MSQG-Q, the SQSs-I was applied to assess the heavy metal risk in sediments, because it was calculated based on Grade I of EQSSW, which could effectively protect most aquatic organisms (CSEPA, 2002). Results showed that $\mathrm{Zn}$ and $\mathrm{Cu}$ were the major contributors to sediment contamination, while Pb exhibited lower level. The mSQG-Q values at sites JL1, JL2, and JL6 ranged from 0.1 to 1 , implying that their potential combined bio-toxic effect levels were moderate. The $\mathrm{MSQG}-\mathrm{Q}$ values at other sites were below 0.1, presenting unimpacted or lowest potential bio-toxic effects. For JH, all heavy metals were lower than SQS- $\mathrm{I}_{\mathrm{JH}}$ values, which indicated lower pollution levels. The $\mathrm{MSQG}-\mathrm{Q}$ values ranged from 0.1 to 1 , which showed moderate impact potential biotoxic effects.

To investigate the feasibility of basin-scale heavy metal SQSs, a comparison between the evaluation results of mSQG-Q and $\mathrm{CF}$ (including PLI) was performed. The evaluation results of PLI and CF are illustrated in Table 5. In JL, the CF values of $\mathrm{Cu}$ and $\mathrm{Pb}$ were $<1$, implying low contamination levels. The $\mathrm{CF}$ of $\mathrm{Cd}$ and $\mathrm{Zn}$ ranged from 2.10 to 4.70 and 0.34 to 2.26 , exhibiting a moderate to considerate and a low to moderate contamination degree, respectively. Overall, mean $\mathrm{CF}$ values for all heavy metals were: $\mathrm{Cd}>\mathrm{Zn}>\mathrm{Pb}>\mathrm{Cu}$. For PLI values, the heavy metal pollution level at sites JL6 and JL1 were high compared to other sites. For JH, the CF values of $\mathrm{Cu}$ ranged from 0.96 to 2.89 , with a moderate contamination degree. Sediments in JH suffered from moderate pollution with $\mathrm{Pb}(1<\mathrm{CF}<3)$. The $\mathrm{Cd}$ in JH exhibited the highest contamination degree, followed by $\mathrm{Cu}, \mathrm{Zn}$, and $\mathrm{Pb}$. High PLI values were found in JH13 and JH14, and the lowest PLI value was observed in JH6. Overall, Cd was the major contributor to sediment pollution in $\mathrm{JL}$ and $\mathrm{JH}$ based on CF evaluation.

The evaluation results of $\mathrm{CF}$ and/or PLI were highly variable compared to mSQG-Q based on SQSs. The MSQG-Q showed little difference in the pollution levels among all sites, even presenting

Table 5

The CF and PLI values of heavy metals in sediments in JL and JH.

\begin{tabular}{|c|c|c|c|c|c|}
\hline \multirow[b]{2}{*}{ Sites } & \multicolumn{4}{|c|}{ CF } & \multirow[b]{2}{*}{ PLI } \\
\hline & Cd & $\mathbf{C u}$ & $\mathbf{P b}$ & $\mathbf{Z n}$ & \\
\hline JL1 & 4.00 & 0.63 & 0.63 & 1.96 & 1.33 \\
\hline JL2 & 2.10 & 0.38 & 0.42 & 0.34 & 0.58 \\
\hline JL3 & 2.80 & 0.46 & 0.73 & 1.64 & 1.11 \\
\hline JL4 & 2.60 & 0.52 & 0.48 & 0.51 & 0.76 \\
\hline JL5 & 4.70 & 0.30 & 0.50 & 0.45 & 0.75 \\
\hline JL6 & 3.00 & 0.68 & 0.85 & 2.26 & 1.41 \\
\hline JL7 & 3.40 & 0.54 & 0.45 & 0.46 & 0.79 \\
\hline JL8 & 3.40 & 0.52 & 0.63 & 0.46 & 0.84 \\
\hline Mean & 3.25 & 0.50 & 0.59 & 1.01 & \\
\hline JH1 & 3.00 & 0.96 & 1.08 & 0.91 & 1.30 \\
\hline JH2 & 3.30 & 1.20 & 1.33 & 1.09 & 1.55 \\
\hline JH3 & 3.10 & 1.10 & 1.01 & 0.85 & 1.31 \\
\hline JH4 & 4.40 & 1.74 & 1.73 & 1.63 & 2.15 \\
\hline JH5 & 4.50 & 1.83 & 1.66 & 1.57 & 2.15 \\
\hline JH6 & 2.50 & 1.13 & 1.03 & 0.97 & 1.30 \\
\hline JH7 & 5.00 & 1.82 & 1.81 & 1.77 & 2.32 \\
\hline JH8 & 3.10 & 1.23 & 1.16 & 1.07 & 1.47 \\
\hline JH9 & 2.70 & 1.35 & 1.03 & 1.16 & 1.44 \\
\hline JH10 & 3.40 & 1.61 & 1.01 & 1.50 & 1.70 \\
\hline JH11 & 3.60 & 1.75 & 1.20 & 1.73 & 1.90 \\
\hline JH12 & 3.90 & 1.98 & 1.49 & 1.82 & 2.14 \\
\hline JH13 & 17.30 & 2.11 & 1.12 & 3.10 & 3.36 \\
\hline JH14 & 25.30 & 2.89 & 1.36 & 3.18 & 4.22 \\
\hline Mean & 6.08 & 1.62 & 1.29 & 1.60 & \\
\hline
\end{tabular}

CF: $\quad$ : low degree; $\square$ : moderate degree; $\square$ : considerate degree; $\square$ : very high degree. the same contamination degree, whereas the results of $\mathrm{CF}$ and/or PLI showed pollution levels of sites that were largely different. This was mainly due to the differences in the evaluation principle between mSQG-Q and CF (PLI). Some conventional methods (e.g., CF and/or PLI) used background values to measure the pollution levels of heavy metals in sediments. However, background values in different areas always have large differences, resulting in inaccuracies of evaluation results. Moreover, the complexity and bioavailability of geochemical forms of heavy metals in sediments are also neglected by employing such methods. For SQSs, owing to the focus on bioavailability and toxicity levels of heavy metals in sediments, basin-scale SQSs can avoid the shortcomings of other conventional methods and reflect the actual pollution level of heavy metals in sediments.

Furthermore, the heavy metal SQSs derived from the corresponding SQGs could be applicable to assess corresponding sediment quality in different water function zones, which could facilitate effective management and remediation of heavy metal polluted sediments. Therefore, the basin-scale heavy metal SQGs based on water quality would be a reliable method for SQS establishment.

\section{Conclusions}

The spatial distribution of heavy metals in sediments in JL and $\mathrm{JH}$ were highly variable. Most heavy metals in sediments were dominated by residual fraction, except for $\mathrm{Pb}$ and $\mathrm{Cd}$ in $\mathrm{JH}$. The partition of heavy metals between sediments and porewater were influenced by sediment properties and input of external heavy metals. IWCTU results showed that only several sites might pose long-term toxicity effects to the aquatic organisms in two rivers. For heavy metal SQGs and SQSs, the basin-scale heavy metal SQGs can reasonably classify different grades of sediments in different water function zones, and deduce the corresponding SQSs after normalization and optimization. Moreover, the MSQG-Q based on SQSs showed that heavy metals posed a lower potential bio-toxic effects in both JL and JH. With the comparison of evaluation results based on CF, establishing basin-scale heavy metal SQSs in coastal rivers based on SQGs combined with water quality standards was a feasible task. Notably, the normalized and optimized heavy metal SQGs were directly assumed as SQSs in this study only from a scientific point of view. In reality, the heavy metal SQSs establishment needs to integrate various factors (e.g., technologies and costs). Thus, there has been still much work to be done for establishing heavy metal SQSs.

\section{Author contribution section}

Conceived and designed the experiments: Qunqun Liu, Yanqing Sheng. Performed the experiments: Qunqun Liu, Ming Jiang, Guoqiang Zhao, Changyu Li. Analyzed the data: Qunqun Liu. Contributed reagents/materials/analysis tools: Yanqing Sheng. All authors agree with the contribution and declare that they have no actual or potential competing financial interests.

\section{Declaration of competing interest}

The authors declare that they havno known competing financial interests or personal relationships that could have appeared to influence the work reported in this paper.

\section{Acknowledgments}

This study was supported by the Strategic Priority Research Program of the Chinese Academy of Sciences (CAS) (Grant No.: 
XDA23050203) and the National Natural Science Foundation of China (Grant No.: 41373100). Additional support was provided by the Regional Key Project of STS of CAS (Grant No.: KFJ-STS-QYZX057) and the Key Research and Development Program of Shandong Province (Grant No.: 2019GSF109002).

\section{Appendix A. Supplementary data}

Supplementary data to this article can be found online at https://doi.org/10.1016/j.chemosphere.2019.125596.

\section{References}

Allen, H.E., Van, B.P., Struijs, J., 1993. Acid volatile sulfide. Sci. Total Environ. 134, $1789-1791$.

Alves, C.M., Ferreira, C.M., Soares, H.M., 2018. Relation between different meta pollution criteria in sediments and its contribution on assessing toxicity. Chemosphere 208, 390-398.

Burton Jr., G.A., 2002. Sediment quality criteria in use around the world. Limnology $3,65-76$

Caeiro, S., Costa, M.H., Ramos, T.B., Fernandes, F., Silveira, N., Coimbra, A Medeiros, G., Painho, M., 2005. Assessing heavy metal contamination in Sado Estuary sediment: an index analysis approach. Ecol. Indicat. 5, 151-169.

Chen, H., Chen, R., Teng, Y., Wu, J., 2016. Contamination characteristics, ecological risk and source identification of trace metals in sediments of the Le'an River (China). Ecotoxicol. Environ. Saf. 125, 85-92.

Cheng W.H. Yap, C.K., 2015. Potential human health risks from toxic metals via mangrove snail consumption and their ecological risk assessments in the habitat sediment from Peninsular Malaysia. Chemosphere 135, 156-165.

Chen, Y.Z., Yang, H., Zhang, Z.K., Oin, M.Z., Jin, F., Lü, J.J., 2007. Application of equilibrium partitioning approach to the derivation of sediment quality guidelines for metals in Dianchi Lake. Pedosphere 17, 284-294.

CENPA (China National Environmental Protection Administration), 2002. In: Monitoring and Analysis Methods of Water and Wastewater, fourth ed. China Environmental Science Press, Beijing.

CSEPA (Chinese State Environmental Protection Administration), 2002. Environmental Quality Standards for Surface Water (GB 3838-2002). China Environmental Science Press, Beijing, China.

CSBTS (China State Bureau of Quality and Technical Supervision), 2002. Chinese Marine Sediment Quality Standards (CMSQS, GB 18668-2002). Marine Sediment Quality Standards Press of China, Beijing, China.

Gao, L., Gao, B., Wei, X., Zhou, H.D., Xu, D.Y., Wang, Y.C., 2015. Assessment of metal toxicity and development of sediment quality guidelines using the equilibrium partitioning model for the Three Gorges Reservoir, China. Environ. Sci. Pollut. Res. 22, 17577-17585.

Gu, Y.G., Lin, Q., 2016. Trace metals in a sediment core from the largest mariculture base of the eastern Guangdong coast, South China: vertical distribution, speciation, and biological risk. Mar. Pollut. Bull. 113, 520-525.

Han, C., Qin, Y., Zheng, B., Ma, Y., Zhang, L., Cao, W., 2014. Sediment quality assessment for heavy metal pollution in the Xiang-jiang River (China) with the equilibrium partitioning approach. Environ. Earth Sci. 72, 5007-5018.

Hierro, A., Olías, M., Cánovas, C.R., Martín, J.E., Bolivar, J.P., 2014. Trace metal partitioning over a tidal cycle in an estuary affected by acid mine drainage (Tinto estuary, SW Spain). Sci. Total Environ. 497-498, 18-28.

Huo, S., Xi, B., Yu, X., Su, J., Zan, F., Zhao, G., 2013. Application of equilibrium partitioning approach to derive sediment quality criteria for heavy metals in a shallow eutrophic lake, Lake Chaohu, China. Environ. Earth Sci. 69, 2275-2285.

Islam, M.S., Hossain, M.B., Matin, A., Sarker, M.S.I., 2018. Assessment of heavy metal pollution, distribution and source apportionment in the sediment from Fen River estuary, Bangladesh. Chemosphere 202, 25-32.

Ji, H., Li, H., Zhang, Y., Ding, H., Gao, Y., Xing, Y., 2018. Distribution and risk assessment of heavy metals in overlying water, porewater, and sediments of Yongding River in a coal mine brownfield. J. Soils Sediments 18, 624-639.

Lin, Y., Meng, F., Du, Y., Tan, Y., 2016. Distribution, speciation, and ecological risk assessment of heavy metals in surface sediments of Jiaozhou Bay, China. Hum. Ecol. Risk. Assess. 22, 1253-1267.

Liu, H., Zhang, K., Chai, L., Yang, Z., Yang, W., Liao, Q., Li, H., Liu, Y., 2017. A comparative evaluation of different sediment quality guidelines for metal and metalloid pollution in the Xiangjiang River, Hunan, China. Arch. Environ. Contam. Toxicol. 73, 593-606.

Liu, Q., Jia, Z., Li, S., Hu, J., 2019. Assessment of heavy metal pollution, distribution and quantitative source apportionment in surface sediments along a partially mixed estuary (Modaomen, China). Chemosphere 225, 829-838.

Liu, Q., Wang, F., Meng, F., Jiang, L., Li, G., Zhou, R., 2018a. Assessment of metal contamination in estuarine surface sediments from Dongying City, China: use of a modified ecological risk index. Mar. Pollut. Bull. 126, 293-303.

Liu, X., Jiang, J., Yan, Y., Dai, Y., Deng, B., Ding, S., Su, S., Sun, W., Li, Z., Gan, Z., 2018b. Distribution and risk assessment of metals in water, sediments, and wild fish from Jinjiang River in Chengdu, China. Chemosphere 196, 45-52.

Long, E.R., MacDonald, D.D., 1998. Recommended uses of empirically derived, sediment quality guidelines for marine and estuarine ecosystems. Hum. Ecol. Risk. Assess. 4, 1019-1039.

MacDonald, D.D., Ingersoll, C.G., Berger, T.A., 2000. Development and evaluation of consensus-based sediment quality guidelines for freshwater ecosystems. Arch. Environ. Contam. Toxicol. 39, 20-31.

Ma, T., Sheng, Y., Meng, Y., Sun, J., 2019. Multistage remediation of heavy metal contaminated river sediments in a mining region based on particle size. Chemosphere 225, 83-92.

Ministry of Ecological and Environment of China, 2018. Soil Environmental Quality: Risk Control Standard for Soil Contamination of Agricultural Land (GB156182018) (Beijing).

Morillo, J., Usero, J., Gracia, I., 2004. Heavy metal distribution in marine sediments from the southwest coast of Spain. Chemosphere 55, 431-442.

Neyestani, M.R., Bastami, K.D., Esmaeilzadeh, M., Shemirani, F., Khazaali, A., Molamohyeddin, N., Afkhami, M., Afkhami, S., Dehghani, M., Aghaei, S., Firouzbakht, M., 2016. Geochemical speciation and ecological risk assessment of selected metals in the surface sediments of the northern Persian Gulf. Mar. Pollut. Bull. 109, 603-611.

Pan, K., Wang, W.X., 2012. Trace metal contamination in estuarine and coastal environments in China. Sci. Total Environ. 421, 3-16.

Rauret, G., Lopez-Sanchez, J., Sahuquillo, A., Rubio, R., Davidson, C., Ure, A., Quevauviller, P., 1999. Improvement of the BCR three step sequential extraction procedure prior to the certification of new sediment and soil reference materials. J. Environ. Monit. 1, 57-61.

Sheng, Y.Q., Sun, Q.Y., Shi, W.J., Bottrell, S., Mortimer, R., 2015. Geochemistry of reduced inorganic sulfur, reactive iron, and organic carbon in fluvial and marine surface sediment in the Laizhou Bay region, China. Environ. Earth Sci. 74, $1151-1160$.

Shi, C.Y., Liang, M., Feng, B., 2016. Average background values of 39 chemical elements in stream sediments of China. Earch Sci 41, 234-251 (In Chinese).

Soliman, N.F., Younis, A.M., Elkady, E.M., 2019. An insight into fractionation, toxicity, mobility and source apportionment of metals in sediments from El Temsah Lake, Suez Canal. Chemosphere 222, 165-174.

Tang, W., Duan, S., Shan, B., Zhang, H., Zhang, W., Zhao, Y., Zhang, C., 2016. Concentrations, diffusive fluxes and toxicity of heavy metals in pore water of the Fuyang River, Haihe Basin. Ecotoxicol. Environ. Saf. 127, 80-86.

Toro, D.M.D., Mahony, J.D., Hansen, D.J., Scott, K.J., Carlson, A.R., Ankley, G.T., 1991. Acid volatile sulfide predicts the acute toxicity of cadmium and nickel in sediments. Environ. Sci. Technol. 26, 96-101.

US EPA, 1989. Briefing Report to the EPA Science Advisory Board on the Equilibrium Partitioning Approach to Generating Sediment Quality Criteria. EPA2440252892002, Washington DC.

US EPA, 2002. National Recommended Water Quality Criteria. EPA 822-R-02-047.

US EPA, 2005. Procedures for the Derivation of Equilibrium Partitioning Sediment Benchmarks (ESBs) for the Protection of Benthic Organisms: Metal Mixtures (Cadmium, Copper, Lead, Nickel, Silver, and Zinc). EPA 600-R-02-011.

Wang, J., Liu, G., Wu, H., Zhang, T., Liu, X., Li, W., 2018. Temporal-spatial variation and partitioning of dissolved and particulate heavy metal (loid) $\mathrm{s}$ in a river affected by mining activities in Southern China. Environ. Sci. Pollut. Res. 1-12.

Webster, J., Ridgway, I., 1994. The application of the equilibrium partitioning approach for establishing sediment quality criteria at two UK sea disposal and outfall sites. Mar. Pollut. Bull. 28, 653-661.

Yao, Q., Wang, X., Jian, H., Chen, H., Yu, Z., 2016. Behavior of suspended particles in the Changjiang Estuary: size distribution and trace metal contamination. Mar. Pollut. Bull. 103, 159-167.

Zang, F., Wang, S., Nan, Z., Ma, J., Li, Y., Zhang, Q., Chen, Y., 2017. Immobilization of $\mathrm{Cu}, \mathrm{Zn}, \mathrm{Cd}$ and $\mathrm{Pb}$ in mine drainage stream sediment using Chinese loess. Chemosphere 181, 83-91.

Zhang, G., Bai, J., Xiao, R., Zhao, Q., Jia, J., Cui, B., Liu, X., 2017. Heavy metal fractions and ecological risk assessment in sediments from urban, rural and reclamationaffected rivers of the Pearl River Estuary, China. Chemosphere 184, 278-288.

Zhang, Z., Lu, Y., Li, H., Tu, Y., Liu, B., Yang, Z., 2018. Assessment of heavy metal contamination, distribution and source identification in the sediments from the Zijiang River, China. Sci. Total Environ. 645, 235-243. 